\title{
Os Desafios da Escola no Enfrentamento e na Prevenção do Cyberbullying
}

\author{
Herik Zednik ${ }^{1}$, Thales S. Arrais ${ }^{1}$, Renato S. do Vale ${ }^{2}$, Eder Paulus M. Guerra ${ }^{3}$ \\ ${ }^{1}$ Centro de Ciência e Tecnologia (CCT)- Mestrado Profissional em Computação \\ Aplicada (MPCOMP) - Universidade Estadual do Ceará (UECE) \\ ${ }^{2}$ Núcleo de Estudos de Pós-graduação em Filosofia (NUFIL) - Universidade Estadual \\ do Ceará (UECE) \\ ${ }^{3}$ Universidade Estadual Vale do Acaraú \\ herik.zednik@ufrgs.br, thalesarrais.ts@gmail.com \\ renatodovaleuece@gmail.com, ederpaulus@yahoo.com.br
}

\begin{abstract}
The fast and intense technological change has provided more access to information, but it also poses new challenges to the 21 st Century School. Such challenges are consolidated by the risks of improper use of digital media. Among such risks, it is the cyberbullying. This highlights the need to prepare the school for the development of an effective police to empower young people and school staff to combat and prevent this unethical and aggressive behavior. This study aims to understand and analyze the cyberbullying culture as an strategy of combat and prevention of this phenomenon in the school context. The methodology used in this paper is characterized as a theoretical and descriptive.
\end{abstract}

Resumo. A rápida e intensa mudança tecnológica, ao mesmo tempo em que, tem proporcionado mais acesso à informação, também impõe novos desafios à escola do século XXI. Esses desafios se consolidam em torno dos riscos potencializados pelo uso indevido das mídias digitais. Entre eles, destaca-se o cyberbullying. Isso evidencia a necessidade de preparar a escola para o desenvolvimento de uma política eficiente que capacite os jovens e equipe escolar para combaterem e prevenirem esse comportamento antiético e agressivo. Esse estudo objetiva compreender e analisar a cultura do cyberbullying como estratégia de enfrentamento e prevenção desse fenômeno no contexto escolar, por meio de uma pesquisa teórico-descritiva.

\section{Introdução}

É notório o enorme grau de liberdade proporcionado pelas tecnologias digitais, por meio da socialização de ideias, conteúdos e informações. No mundo virtual, as pessoas, notoriamente, ganharam voz e liberdade de expressão como nunca antes na história da humanidade. No entanto, como consequência, esse enorme potencial trouxe proporcionais desafios educacionais relacionados ao uso consciente dos recursos tecnológicos. Em face dessa realidade, alguns comportamentos antiéticos, agressivos e indesejados, apesar de serem antigos, alcançaram maior dimensão, pois foram potencializados pelas mídias digitais.

Este artigo centra-se na compreensão e na análise da cultura do cyberbullying, de modo que se propõe como estratégia de enfrentamento e prevenção desse fenômeno no 
contexto escolar. Acredita-se que a reflexão e o debate acerca do tema colaboram com a identificação e o conhecimento dessa prática, bem como seu combate, o que pode ajudar na minimização desse problema. A finalidade é fomentar uma consciência crítica, a partir do reconhecimento e da análise da cultura do cyberbullying.

Esta pesquisa se desenvolve através de uma metodologia teórico-descritiva, cujos procedimentos técnicos utilizaram-se da pesquisa de campo, com aplicação de 350 questionários, em 35 escolas das redes pública e privada do Ceará/Br, em distintas cidades. A opção pela pesquisa de campo justifica-se por esta coletar "[...] informações e/ou conhecimentos acerca de um problema para o qual se procura uma resposta, ou de uma hipótese, que se queira comprovar ou, ainda, descobrir novos fenômenos ou as relações entre eles". [Lakatos, 2003, p. 186].

Os pontos principais que se estabelecem neste trabalho são: introdução ao contexto da problemática; descrição e conceituação de termo bullying e cyberbullying; papel da escola no enfrentamento e na prevenção ao cyberbullying; análise dos dados coletados; e, finalmente, exposição das considerações finais, com ênfase em reflexões inerentes ao próprio estudo.

\section{Cyberbullying: o bullying da era digital}

O bullying pode ser conceituado como um conjunto de comportamentos violentos presentes na escola e em outras instituições sociais. Para Barbosa Silva [2010, p. 22], "[...] o termo bullying pode ser adotado para explicar todo comportamento agressivo, cruel, proposital e sistemático inerente às relações interpessoais". Compreende-se, segundo Gabriel [2013, p. 145], “[...] em três formas básicas de agressão: emocional, verbal e física". Quando o bullying é realizado por meio das mídias digitais, ele é nomeado de cyberbullying, indicado ao uso do "[...] espaço virtual para intimidar e hostilizar uma pessoa (colega de escola, professores, ou mesmo desconhecidos), difamando, insultando ou atacando covardemente" [Brasil, 2016, online].

Outrossim, o cyberbullying caracteriza-se como a prática de constranger, amedrontar, ridicularizar e humilhar qualquer pessoa, conhecida ou não, por canal virtual (posts em redes sociais, sites, blogs, mensagens de e-mail, SMS), por meio de difamação, ameaça ou marginalização. Nesse sentido, conforme Gabriel [2013, p. 150], o cyberbullying pode assumir várias formas, como:

- Envio de mensagens cruéis ou de ameaças para alguém - por e-mail ou telefone celular;

- Disseminação de rumores cruéis on-line sobre alguém - por meio de posts em mídias sociais, sites, mensagens de e-mail etc.;

- Disseminação de conteúdos (fotos, informações íntimas ou sexuais, dados privados etc.) on-line sobre alguém - por meio de posts em mídias sociais, sites, mensagens de e-mail etc.;

- Invasão de conta on-line (mídias sociais, e-mail etc.) de alguém e usar essa conta para postar mensagens prejudiciais, passando-se por ela;

- Simulação da identidade de outra pessoa on-line para ferir ou prejudicar alguém.

Embora o cyberbullying não envolva agressões físicas, ele pode ser mais prejudicial que o bullying. Por ser praticado no universo virtual, esse conteúdo pode ficar disponível por muito tempo na rede, o que pode disseminar, ainda mais, a violência, tornando-a atemporal e, consequentemente, com graves danos psicológicos à 
vítima. Dessa forma, aquele comportamento agressivo (que busca oprimir a vítima, prejudicando-a psicológica e fisicamente) é a principal característica do bullying. Esse tipo de agressividade, presente em diferentes contextos sociais, com forte incidência na escola, prejudica funções cognitivas das crianças e dos adolescentes que a sofrem, tornando-se necessário o conhecimento dessa temática para posterior intervenção [Carvalho 2005].

Embora seja um tema em voga, Abramovay [2002] afirma que o fenômeno da violência na escola ocorre e é analisado de maneira diferente daquela do passado, quando ocorria do professor para os alunos, por meio de castigos. Atualmente, analisam-se os tipos de violência praticados entre alunos, dos alunos contra a propriedade - como no caso do vandalismo - de alunos contra professores e de professores contra alunos. Numa perspectiva mais moderna, o espaço virtual possibilita que a violência transcenda o espaço escolar para um mundo sem limites, sem fronteiras e, aparentemente, impune.

Charlot [2002] assevera que esse fenômeno não é novo, e, sim, as suas formas de manifestação. Muito antes de o Brasil tomar consciência e intervir nesse problema, outros países já estavam a par dessa situação, realizando amplas pesquisas que buscavam identificar as causas e as formas de combate a esse problema, de modo eficaz, com táticas de prevenção. Portanto, "[...] a violência na escola é objeto de debates nos Estados Unidos há três décadas: o Instituto Nacional de Educação afirmava, já em 1978, que a violência na escola era um problema nacional" [Tavares dos Santos 2001, p.110]. A pesquisa $\mathbf{O}$ comportamento saudável das crianças em idade escolar ${ }^{1}$ [HSBC] examinou o bullying, com, aproximadamente, 200 mil crianças, em 40 países, entre 2005 e 2006, conforme se pode visualizar no gráfico abaixo.

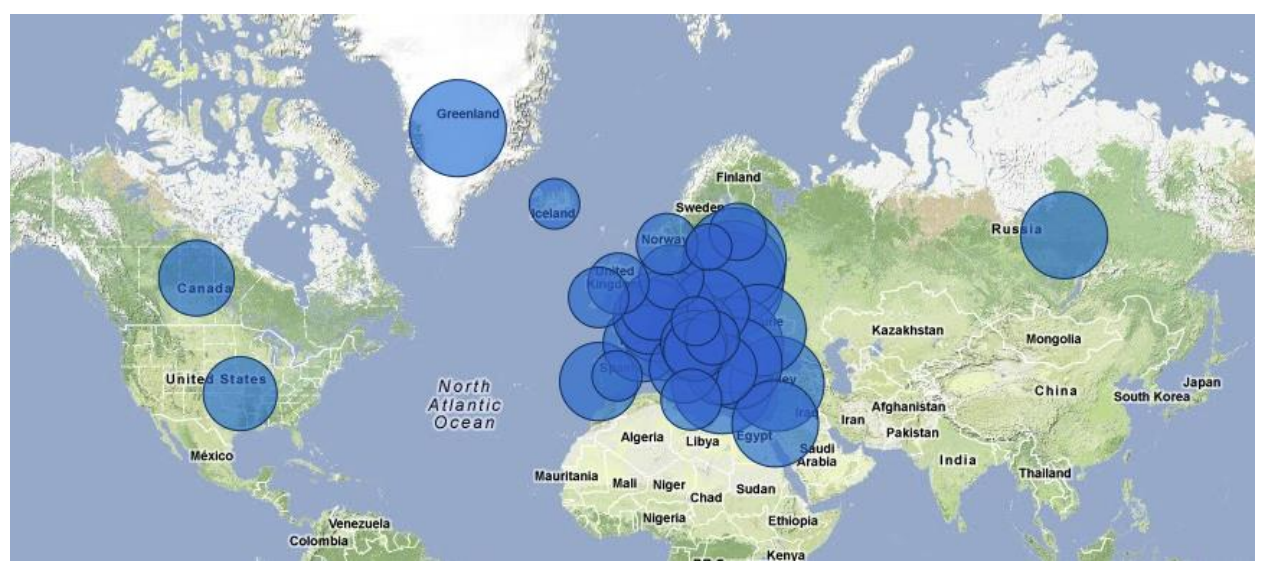

Fonte: Craig [2009]

No Brasil, o Relatório TIC Kids Online Brasil 2014, também buscou compreender situações características do cyberbullying, por meio da aplicação de questionários para crianças e adolescentes de 9 a 10 anos (versão 1), e outro mais detalhado, destinado aos respondentes de 11 a 17 anos (versão 2). Uma primeira dimensão do problema foi coletada a partir de uma pergunta sobre quais conteúdos da Internet eles acreditavam serem capazes de incomodar, chatear ou aborrecer crianças e adolescentes da mesma idade que eles [TIC Kids Online Brasil 2014, 2015].

Reforçando o diagnóstico de 2013, o resultado do relatório de 2015 afirma que:

\footnotetext{
${ }^{1}$ The health behavior in school-aged children
} 
V Congresso Brasileiro de Informática na Educação (CBIE 2016)

Anais do XXII Workshop de Informática na Escola (WIE 2016)

[...] a prática de bullying continua sendo o assunto mais citado pelos jovens $(36 \%)$. Foram codificadas como prática de bullying respostas relacionadas a "ameaças", "contar mentira sobre a minha pessoa", entre outras. [...] Em se tratando das experiências vividas pelos jovens, 27\% afirmam que alguma pessoa agiu de forma ofensiva ou que lhes chateou nos últimos 12 meses, sendo que $15 \%$ afirmaram que essa situação ocorreu na Internet. [TIC Kids Online Brasil 2014, 2015].

A seriedade da violência escolar tem suscitado a busca de explicações e intervenções, tanto por parte de educadores, como de movimentos sociais organizados ou da população em geral. O objetivo seria compreender a manifestação, seja em sua forma física - que é aquela que ocorre de uma maneira que afete o corpo da vítima - ou em sua forma psicológica.

Assim, a escola, como espaço de convivência e de relações entre pessoas, envolve diversos comportamentos e personalidades. É, durante as expressões desses comportamentos e personalidades, que a convivência e a relação entre pessoas pode tornar-se mais violenta. Assim, a violência na escola, nesse contexto, configura-se:

[...] enquanto vontade de estruir, de viltar, de atormentar, que causa problema - e que causa mais problema ainda em uma instituição que, como a escola, inscreve-se na ordem da linguagem e da troca simbólica e não da força física [Charlot 2002, p.436].

Dan Olweus, pesquisador da Universidade de Berger, na Noruega, foi um dos primeiros a pesquisar sobre a temática violência na escola caracterizada como bullying. Notou-se uma mudança na dinâmica de atos violentos no espaço escolar. Nesse contexto, convém mencionar que a escola não é um espaço neutro às questões sociais. Muito pelo contrário, ela recebe influências e influencia a sociedade, e a questão da violência, no espaço escolar, é mais uma manifestação de questões sociais que afetam a própria escola, visto que "[...] as relações de sociabilidade passam por uma nova mutação, mediante processos simultâneos de interação comunitária e de fragmentação social, de massificação e de individualização, de seleção e de exclusão social" [Tavares dos Santos 2001, p.117-118].

Para o autor, a sociedade vem sofrendo uma série de mudanças, no que diz respeito às relações humanas. A violência, nesse cenário, seria resultado de relações conflituosas, afetando também a escola. Tavares dos Santos [2001, p. 107] afirma que como consequência "[...] dos processos de fragmentação social e de exclusão econômica e social, emergem as práticas de violência como norma social particular de amplos grupos da sociedade, presentes em múltiplas dimensões da violência social e política contemporânea".

As manifestações de violência características do bullying tanto podem ser físicas como psicológicas. Os alunos que fogem ao padrão corporal de beleza e estética fomentados pela sociedade da Modernidade Tardia são alvo desse fenômeno, o qual se manifesta por meio de apelidos pejorativos, xingamentos, gestos ofensivos etc. Também existe uma relação de força, em que os mais fracos são vítimas, e os mais fortes, agressores, com agressão psicológica (apelidos pejorativos, gestos ofensivos) e física.

Na relação violenta que caracteriza o bullying, os sujeitos dessa relação mantêmse em desigualdade de poder, pois o praticante sempre mantém as vítimas sob seu controle e faz isso diversas vezes, com manifestações violentas, seja de forma psicológica ou física. Além disso, intimida aqueles ao seu redor para que não interfiram, 
o que deixa a vítima incapacitada para reagir. Assim, “[...] o abuso de poder, a intimidação e a prepotência são algumas das estratégias adotadas pelos praticantes de bullying (os bullies) para impor sua autoridade e manter suas vítimas sob total domínio" [Barbosa Silva 2010, p.21].

Não obstante, o advento das Novas Tecnologias da Informação e Comunicação (NTIC) levou estas ações violentas para os espaços de convivência virtual. Assim, Cyberbullying é um tipo de violência eletrônica, com as agressões acontecendo através das NTIC. O panorama da violência, no ambiente virtual, fomenta as seguintes questões: quais as características das manifestações violentas no mundo virtual? Quem mais sofre essa violência? Qual o papel da escola no combate ao cyberbullying?

A pergunta que fazem os educadores brasileiros e de tantos outros países, na atualidade, é: como intervir e combater essa violência? Não só eles, mas qualquer um que já passou pela escola, e sofreu com essa agressão, se pergunta como evitar esse constrangimento para crianças e adolescentes. A seção 3 busca refletir acerca desses questionamentos.

\section{O Papel da Escola no Enfrentamento e na Prevenção ao Cyberbullying}

Prevenir práticas de violência, por meio das Tecnologias Digitais, e reduzir o número de vítimas e agressores no espaço virtual (em especial dos jovens em idade escolar) parte de um ponto básico, mas fundamental, que estabelece as bases para uma grande reforma na escola: promover o conhecimento para se protegerem dos riscos que representam as TIC [Beranuy Fargues et al 2009]. Consequentemente, eleva a necessidade de uma "[...] formação com ampla discussão acerca da ciberética, pois a ausência de um forte direcionamento ético e consciente no uso da Internet - por parte de professores e alunos na prática educativa - pode ensejar mau uso e, até mesmo, distúrbios comportamentais [Zednik 2015].

Para a escola, o primeiro passo é admitir que o problema existe, pode ser vivenciado a qualquer momento e, necessariamente, precisa ser enfrentado [Jones et al 2012]. Uma vez admitida a situação de risco, uma série de ações sistemáticas e progressivas colaboram para promover mudanças significativas na educação dos alunos [Prieto Quezada, 2015], de maneira que desenvolvam o comportamento consciente e evite que o estudante possa se colocar numa situação de vítima ou agressor. O Quadro 1 apresenta um conjunto de ações elencadas por Zednik [2015] e Gabriel [2013] com o intuito de promover uma política anti-bullying e práticas de intervenção na escola.

\begin{tabular}{|l|l|}
\hline \multicolumn{1}{|c|}{ Zednik [2015, p. 257] } & \multicolumn{1}{|c|}{ Gabriel [2013, p. 151] } \\
\hline $\begin{array}{l}\text { 1. admitir a situação de risco a que todos os sujeitos } \\
\text { estão expostos; }\end{array}$ & $\begin{array}{l}\text { 1. educar os jovens sobre cyberbullying, explicando } \\
\text { que é errado, antiético e que pode trazer consequências } \\
\text { graves; }\end{array}$ \\
\hline $\begin{array}{l}\text { 2. instituir uma equipe escolar para direcionar } \\
\text { protocolos de intervenção; }\end{array}$ & $\begin{array}{l}\text { 2. encorajar os jovens a contarem para um adulto se o } \\
\text { cyberbullying estiver acontecendo, assegurando que, se } \\
\text { forem vítimas, não é culpa deles e que não serão } \\
\text { punidos por revelarem o fato; }\end{array}$ \\
\hline $\begin{array}{l}\text { 3. desenvolver campanhas de sensibilização para } \\
\text { professores, estudantes e famílias; }\end{array}$ & $\begin{array}{l}\text { 3. instruir os jovens a guardar as mensagens de } \\
\text { cyberbullying como prova de que está acontecendo; }\end{array}$ \\
\hline $\begin{array}{l}\text { 4. estabelecer uma política rigorosa e avançada } \\
\text { sobre a violência virtual com o apoio dos } \\
\text { pais/responsáveis, como estratégia de preparação } \\
\text { para se protegerem dos perigos da Internet; }\end{array}$ & $\begin{array}{l}\text { 4. educar os jovens sobre segurança da informação - } \\
\text { senhas, endereços de contas, contatos, privacidade etc., } \\
\text { dispositivos móveis (celulares e tablets) acessíveis em }\end{array}$ \\
\hline
\end{tabular}


V Congresso Brasileiro de Informática na Educação (CBIE 2016)

Anais do XXII Workshop de Informática na Escola (WIE 2016)

\begin{tabular}{|l|l|}
\hline & locais em que outras pessoas possam usá-los; \\
\hline $\begin{array}{l}\text { 5. criar práticas de intervenção educacional } \\
\text { relacionadas aos temas: Bullying, Cyberbullying, } \\
\text { violência escolar; }\end{array}$ & $\begin{array}{l}\text { 5. educar os jovens sobre riscos pessoais decorrentes } \\
\text { do compartilhamento de informações on-line. }\end{array}$ \\
\hline $\begin{array}{l}\text { 6. integrar ao programa curricular conteúdos sobre } \\
\text { o comportamento violento na rede e prevenção de } \\
\text { riscos; }\end{array}$ & \\
\hline $\begin{array}{l}\text { 7. promover a formação continuada de professores } \\
\text { que abarquem o tema da violência eletrônica e o } \\
\text { conhecimento sobre sua prevenção; }\end{array}$ & \\
\hline $\begin{array}{l}\text { 8. avaliar e monitorar sistematicamente a eficiência } \\
\text { e a qualidade de todas as estratégias de intervenção; }\end{array}$ & \\
\hline $\begin{array}{l}\text { 9. personalizar as ações de intervenção e prevenção } \\
\text { na escola por meio do conhecimento proveniente de } \\
\text { suas próprias investigações internas; }\end{array}$ & \\
\hline $\begin{array}{l}\text { 10. promover intercâmbio de experiências com } \\
\text { outras escolas. }\end{array}$ & \\
\hline $\begin{array}{l}\text { 11. implementar na escola um programa de sólida } \\
\text { formação ciberética. }\end{array}$ & \\
\hline
\end{tabular}

\section{Quadro 1 - Política anti-bullying}

Este processo deve começar a partir da direção da escola [Ibáñez Etxeberria et al 2012], uma vez que é a Gestão que tem o poder de mobilizar todos os agentes educativos. Afinal, qualquer iniciativa que começa a partir de outros agentes educativos, como pais ou professores, permanece como uma intervenção isolada, com pouca projeção e, consequentemente, com pouco impacto na aprendizagem dos alunos. $\mathrm{O}$ núcleo gestor da escola é a espinha dorsal que possibilita criar estratégias que realmente gerem progresso nesta área.

No entanto, embora a alavanca estrutural para iniciar a integração de práticas educativas conscientes com as TIC nas escolas tenha como ponto de partida o núcleo gestor, geralmente é o professor o agente educativo que detecta a necessidade de abordar o problema da violência virtual [Kvavik 2005]. Normalmente, é o professor que, em nível informal (ou seja, sem que haja qualquer tipo de investigação criada especificamente para localizar o problema), é capaz de perceber um desvio de comportamento em sua sala de aula. Os professores podem identificar, claramente, os alunos que têm um maior potencial para praticar atos violentos na escola ou no mundo digital.

Geralmente, a forma mais usual de identificação dá-se a partir de condutas ou más práticas no uso das TIC, o que o professor visualiza quando os alunos utilizam algum elemento de tecnologia digital na sala de aula, com ou sem consentimento de uso [Díaz Barriga 2008]. A maioria dos alunos não está ciente de que algumas condutas são negativas para eles e seus pares, e que seu comportamento pode não ser ético. Em muitos casos, os alunos nem percebem sua mudança de comportamento e atitudes. Nesse sentido, os professores têm duas tarefas: fazer com que seus alunos compreendam que determinados comportamentos ultrapassam os limites da licitude e transferir essa preocupação aos demais colegas professores de outras áreas de conhecimento, para que eles possam permanecer vigilantes em relação àqueles alunos propensos à prática do cyberbullying [Reig 2013].

Uma vez constatada a gravidade do problema e a necessidade crescente de criar estratégias na sala de aula, para abordar a problemática, o professorado deve estabelecer 
contato com o núcleo gestor e justificar essa realidade. O próximo desafio, tanto do núcleo gestor quanto do corpo docente, é identificar, no alunado, a origem do problema. Ele pode ser causado por meio de maus comportamentos aprendidos na própria família, com amigos, ou serem apenas experiências que nos fazem identificar uma atitude imoderada acionada pelas TIC [Reig 2013].

Em muitos casos de prática do cyberbullying desenvolvidas pelos alunos, segundo Zednik, Lopez e Tarouco [2015, p. 3], observa-se que o uso indevido das TIC, há uma origem não especificamente relacionada à tecnologia, mas que é percebida a partir dela, por duas razões: "[...] a fácil acessibilidade ao evento de risco; e as redes sociais, especialmente, são plataformas digitais que funcionam como campos férteis para revelar comportamentos pré-existentes". Uma vez posta em prática a parceria entre professores e núcleo gestor, estratégias de pesquisa podem ser geradas para fornecer informações sobre as características desses comportamentos [Morales 2015].

A parceria deve ser estendida, também, às famílias, para deixá-las em alerta sobre a situação de um risco potencial que estão vivendo, ou que possam viver num futuro próximo, por seus filhos. A ideia é iniciar um diálogo que facilite a integração da família, de maneira que seja mais um agente educacional no combate ao cyberbullying [Reig 2013].

\section{Metodologia e Análise dos Dados Coletados}

Esta pesquisa, quanto ao objetivo, caracteriza-se como teórico-descritiva, pois tem por finalidade a descrição das "[...] características de determinada população ou fenômeno ou o estabelecimento de relações entre variáveis. Envolvem o uso de técnicas padronizadas de coleta de dados: questionário e observação sistemática" [Gil 1991].

Inicialmente, realizamos um levantamento bibliográfico sobre o bullying e o cyberbullying, confrontando-os com a violência escolar. A fundamentação teórica desta pesquisa conta com autores como Abramovay [2002], Charlot [2002), Tavares dos Santos [2001], Carvalho [2005], Barbosa Silva [2010]. Todos esses autores, em seus estudos, tratam da temática violência na escola, analisando conceitos e propondo alternativas, além de Gabriel [2013] e Zednik [2015] que tratam, em seus trabalhos, do tema cyberbullying.

A pesquisa de campo aplicou 350 questionários, em 35 escolas das redes pública e privada do Ceará/Br. Os respondentes cursavam do $6^{\circ}$ ano do Ensino Fundamental ao $3^{\circ}$ ano do Ensino Médio. Tratava-se de 56,7\% meninas e 43,3\% meninos.

Os questionários foram estruturados na Escala de Likert. Esta escala consiste em uma série de afirmações referentes a um determinado objeto atitudinal [Guerra, 2007]. Para cada uma das afirmações, o entrevistado tem algumas opções de resposta, e deve assinalar com um $\mathrm{X}$ a opção que melhor reflita sua opinião sobre o item em questão [Guerra, 2007]. A coleta dessas informações contou com formulários on-line ${ }^{2}$ de autopreenchimento, disponível no Google Drive, visando a oferecer maior privacidade ao jovem, no momento da entrevista. O questionário é formado por um conjunto de 16 questões que abordam o tema da segurança eletrônica e conta com 3 questões direcionadas ao tema cyberbullying.

\footnotetext{
${ }^{2}$ https://docs.google.com/spreadsheets/d/1SK96hf9MIdVRThYm2tUlnaE5U3E1kIn52SRAYDBwoe4/edi
} t?usp=sharing 
Com base nas informações coletadas, a pesquisa apontou que 41,6\% dos respondentes já tiveram fotos suas postadas sem seu consentimento e que não gostaram da exposição. A exibição da imagem, em muitos casos, acarreta constrangimento aos jovens. Em situações mais graves, quando estes são mais fragilizados emocionalmente, podem ocasionar sérios transtornos emocionais.

O estudo revela, também, que $41,5 \%$ dos respondentes afirmaram que pessoas já escreveram coisas sobre eles, das quais não gostaram. O grande desafio da escola, diante desse dado, é saber diferenciar os problemas normais de relacionamento entre pares, dos problemas de violência virtual que trazem consequências emocionais severas ao jovem. Quando o caso é um problema simples de relacionamento entre pares, o indicado é que esses problemas sejam enfrentados e solucionados pelos próprios jovens, sem intervenção do adulto, como parte do seu desenvolvimento emocional saudável e da formação do seu caráter. Por outro lado, o estudo revela, também, que, quando a agressão vem dos seus pares, isso incomoda muito mais do que quando escritas por estranhos. $\mathrm{O}$ fato de as agressões virem pelas redes sociais, sendo este um espaço de intensa exposição, também contribui para que o ato tome proporções maiores que uma simples contrariedade de relacionamento.

Entre os entrevistados, 7,4\% confirmam que já foram vítimas de cyberbullying, enquanto $4 \%$ admitem já terem praticado cyberbullying com outras pessoas, enquanto $15,7 \%$ afirmam que já foram espectadores em alguma situação de cyberbullying. Os sujeitos envolvidos em atos violentos são afetados de alguma maneira, mesmo que de forma diferente - seja o agressor que se satisfaz, seja o agredido que é afetado física ou psicologicamente. A violência, nesse caso, está ligada à agressão afetando o outro, com a opressão. Para Charlot [2002], a agressividade é algo psíquico, da ordem da frustração, e a agressão é um ato de brutalidade física ou verbal.

A questão do cyberbullying, embora ultrapasse as fronteiras da escola, é mais uma manifestação de questões sociais que afetam a escola. Na esteira de Castel [1998], Giddens [1966], Jameson [1996] e Sousa Santos [1994], citado por Tavares dos Santos [2002, p.117-118], “[...] as relações de sociabilidade passam por uma nova mutação, mediante processos simultâneos de interação comunitária e de fragmentação social, de massificação e de individualização, de seleção e de exclusão social".

A sociedade vem sofrendo uma mudança no que diz respeito às relações humanas. A violência seria resultado de relações conflituosas, afetando, de igual modo, a escola. Ao recorrer a Elias [1990, 1993], Tavares dos Santos [2001, p.107] afirma: "Como efeito dos processos de fragmentação social e de exclusão econômica e social, emergem as práticas de violência como norma social particular de amplos grupos da sociedade, presentes em múltiplas dimensões da violência social e política contemporânea".

\section{Considerações Finais}

Neste estudo, foi previamente consenso que a investigação teria por objetivo compreender e analisar a cultura do cyberbullying como estratégia de enfrentamento e prevenção desse fenômeno no contexto escolar. $\mathrm{O}$ alcance desse objetivo colabora para ajudar na reflexão e no debate acerca do tema. A identificação e o conhecimento dessa prática favorecem o combate e a minimização desse problema. A finalidade é fortalecer os educadores, por meio da formação de uma consciência crítica, que passa pelo 
V Congresso Brasileiro de Informática na Educação (CBIE 2016)

Anais do XXII Workshop de Informática na Escola (WIE 2016)

reconhecimento e pela análise da cultura do cyberbullying e se consolida em ações de uma política anti-bullying ou anti-cyberbullying na escola, bem como na família, além de poder se estender para a comunidade em geral.

Entender a evolução mundial de comportamentos violentos presentes no meio escolar é necessário para compreender as ações violentas no nosso cotidiano e, com isso, desenvolver meios que contribuam para a diminuição de tais ocorrências no espaço escolar.

\section{Referências}

Abramovay, M. (2002) "Violências nas escolas", Brasília: UNESCO Brasil, Rede Pitágoras, Coordenação DST/AIDS do Ministério da Saúde, a Secretaria de Estado dos Direitos Humanos do Ministério da Justiça, CNPq, Instituto Ayrton Senna, UNAIDS, Banco Mundial, USAID, Fundação Ford, CONSED, UNDIME. <unesdoc.unesco.org/images/0013/001339/133967por.pdf>Acesso em: 24/03/16.

Barbosa Silva, A. B. (2010) "Bullying: mentes perigosas nas escolas”, RJ: Objetiva.

Beranuy Fargues, M.; chamarro Lusar, A.; Graner Jordania, C.; Carbonell Sánchez, X. (2009) "Validación de dos escalas breves para evaluar la adicción a Internet y el abuso de móvil”. Psicothema, Vol. 21, nº 3, pp. 480-485.

Brasil. Senado Federal. (2016) "7 tipos mais comuns de bullying virtual que você pode denunciar", <http://senadofederal.tumblr.com/post/141837011027/7-tipos-mais-comunsde-bullying-virtual-que-você>. Acesso em: 28 mar. 2016.

Carvalho, Marilia Pinto de. (2005) "Violências na escola: o "bullying" e a indisciplina", In: Debate: violência, mediação e convivência na escola. 2005. <http://cdnbi.tvescola.org.br/resources/VMSResources/contents/document/publications Series/215810Debateviolencia.pdf >. Acesso em: 19/03/16.

Charlot, Bernard (2002) "A violência na escola: como os sociólogos franceses abordam essa questão", Sociologias, Porto Alegre, ano 4, no 8, jul/dez 2002, p. 432-443. $<$ www.scielo.br/pdf/soc/n8/n8a16.pdf >. Acesso em: 15/03/16.

Craig, W., et al. (2009) (September 21). "A cross-national profile of bullying and victimization among adolescents in 40 countries." PubMed Central: NIHPA Author Manuscripts. The Health Behavior in School-Aged Children (HBSC) survey during the 2005-2006 school year studied bullying among approximately 200,000 adolescents in 40 countries.

Díaz Barriga, F. (2008) “TIC y competencias docentes del S. XXI. Los desafíos de las TIC para el cambio educativo. La educación que queremos para la generación de los bicentenários". Pp 139-155. http://www.oei.es/metas2021/LASTIC2.pdf

Gabriel, M. (2013) “Educar: a (r)evolução digital na educação,” São Paulo: Saraiva.

GIL, A. C. (1991) "Métodos e técnicas de pesquisa social” 3. ed. São Paulo: Atlas.

Ibáñez Etxeberria, A.; Vicent Otaño, N.; Asensio Brouard, M. (2012) “Aprendizaje informal, patrimonio y dispositivos móviles. Evaluación de una experiencia en educación secundaria". Didáctica de las ciências experimentales y sociales. $\mathrm{N}^{\mathrm{o}} 26,3-18$. file:///C:/Users/cinep/Downloads/1937-5981-1-PB.pdf

Jones, C.; Ramanau R.; Cross S. y Healing G. (2012) "Net generation or Digital Natives: Is there a distinct new generation entering university?" Computers and Education 722-732, 
V Congresso Brasileiro de Informática na Educação (CBIE 2016)

Anais do XXII Workshop de Informática na Escola (WIE 2016)

http://ac.els-cdn.com/S0360131509002620/1-s2.0-S0360131509002620-

main.pdf?_tid=5e7b16e8-b838-11e4-b628-

00000aab0f27\&acdnat=1424351477_7423aa32897f1b3771ea1b8ce0a1880f

Kvavik, R. (2005) "Convenience, communications, and control: How students use technology". In D. G. Oblinger, \& J. L. Oblinger (Eds.), Educating the net generation, an Educause e-book publication. <https://net.educause.edu/ir/library/pdf/pub7101.pdf>

Lakatos, E.M., Marconi, M. de A. (2013) "Fundamentos de metodologia científica" 5. ed. São Paulo: Atlas, 2003

Morales Capilla, M.; Trujillo Torres, J. M. e Raso Sánchez, F. (2015) "Percepciones acerca de la integración de las TIC en el processo de enseñanza-aprendizaje de la Universidad”. Pixel-Bit. Revista de Medios y Educación. $\mathrm{N}^{\mathrm{o}} 46 . \quad \mathrm{p}$ 103-117. http://www.slideshare.net/YESSICACORREAMARTINEZ/revista-de-medios-yeducacion

Prieto Quezada, M. T. (2015) "Redes sociales y ciberbullyng. Tema emergente en la investigación educativa". $3^{\circ}$ Congreso Internacional de Investigación educativa. Educación y Globalización. INIE. Universidad de Costa Rica. http://inie.ucr.ac.cr/tercercongreso/memoria/documentos/12/redessocialesyciberbullyingtemaemergente.pdf

Reig, D. (2010) "Los jóvenes están reclamando profesores y familiars más formados en las herrameintas de internet". Euskadi+innova. Govierno Vasco. http://www.euskadinnova.net/es/innovacion-social/entrevistas/propios-jovenes-estanreclamando-profesores-familiares-formados-herramientas-internet/385.aspx

Tavares dos Santos, J. V. (2002) "A violência na escola, uma questão social global” Buenos Aires: $\quad$ CLACSO, $<$ biblioteca.clacso.edu.ar/clacso/gt/20101109035918/5dossantos.pdf>.

p.117-133.

Tavares dos Santos, J. V. (2001) "A violência na escola: conflitualidade social e ações civilizatórias" EducPesq vol.27 no.1 São Paulo Jan./June <http://www.scielo.br/scielo.php?script=sci_arttext\&pid=S151797022001000100008>. Acesso em: 28/03/16.

TIC Kids Online Brasil 2014 (2015) "Pesquisa sobre o uso da internet por crianças e adolescentes no Brasil”, São Paulo: Comitê Gestor da Internet no Brasil, 2015. $<$ http://cetic.br/publicacao/pesquisa-sobre-o-uso-da-internet-por-criancas-eadolescentes-no-brasil-tic-kids-online-brasil-2014/>

Zednik, H. (2015) "e-Maturity: Gestão da Tecnologia numa Perspectiva de Melhoria do Desempenho Pedagógico". Tese (Doutorado) - Universidade Federal do Rio Grande do Sul, Centro de Estudos Interdisciplinares em Novas Tecnologias na Educação, Programa de Pós Graduação em Informática na Educação, Porto Alegre, 318 f.

Zednik, H.; Lopez, C.; Tarouco, L. M. R. (2015) “Os principais riscos à saúde associados ao uso das tecnologias digitais: o papel da escola frente a esse desafio" In: XV Safety, Health and Environment World Congress - SHEWC'2015, 2015, Porto/ Portugal. Keeping Planet "Water Earth" Safe and Sound: a challenge to Science and Technology. São Paulo: Copec, v.15. 